\title{
Implante ósseo cortical alógeno conservado em mel na reconstrução de falha óssea diafisária em fêmur de cães: avaliação clínica e radiográfica
}

\author{
Honey preserved cortical allografts in the repair of diaphyseal femoral defect in dogs: clinical and \\ radiographic evaluation
}

\begin{abstract}
Marcelo Meller Alievi I João Eduardo Wallau Schossler ${ }^{\mathrm{II}}$ Luciana Dambrósio Guimarães ${ }^{\mathrm{III}}$ Ana Néri Christo de Oliveira ${ }^{\text {IV }}$ Carolina Kist Traeslel ${ }^{\text {IV }}$ Patrícia Almeida Ferreira ${ }^{\text {IV }}$
\end{abstract}

\section{RESUMO}

Foi realizada falha segmentar de $5 \mathrm{~cm}$ na região diafisária do fêmur de 14 cães adultos, sendo utilizado implante ósseo cortical alógeno conservado em mel para a sua reconstrução. $O$ implante foi estabilizado no leito receptor por meio de uma placa de compressão dinâmica e oito parafusos corticais. Foram realizadas avaliações clínicas e radiográficas periódicas por até 360 dias. A porcentagem de incorporação das interfaces foi de 79,2\%, e o tempo médio necessário para a incorporação foi de 67,1 dias, variando entre 45 e 90 dias. Não foi verificada diferença significativa entre o tempo de incorporação das interfaces proximal e distal. As principais complicações foram não-união, fratura e reabsorção intensa do implante. Apesar das complicações, é possível concluir que o implante ósseo cortical alógeno conservado em mel é opção viável para a reconstrução óssea.

Palavras-chave: enxertos ósseos, cirurgia ortopédica, trauma, banco de ossos, mel.

\section{ABSTRACT}

Fourteen adult mongrel dogs were used to evaluate the honey preserved cortical allografts in the repair of diaphyseal femoral defect. The allografts were inserted into a $5 \mathrm{~cm}$ segmental defect created in the mid-diaphysis of the right femur in each dog. The bones were stabilized with a dynamic compression plate and eight bone screws. Healing was followed clinically and femora were evaluated radiographically, periodically. Nineteen (79.2\%) of the twenty-four host-graft interfaces were radiographically incorporated. Average time to allograft incorporation was 67.1 days (range 45 days to 90 days). There was no statistical difference in the allograft

\begin{abstract}
incorporation time between proximal and distal host-graft interfaces. Complications observed were nonunion, allograft fracture, and allograft resorption. The conclusion is that despite the complications, honey preserved cortical allografts are a viable option to bone reconstruction.
\end{abstract}

Key words: bone grafts, orthopedic surgery, trauma, bone banking, honey.

\section{INTRODUÇÃO}

As afecções ortopédicas em cães e gatos têm papel de destaque na rotina de um hospital ou clínica veterinária, não é raro, portanto, que o ortopedista se depare com fraturas cominutivas de ossos longos, neoplasias ósseas, não-uniões ou uniões viciosas de fraturas. Uma das principais opções para o tratamento dessas alterações é a substituição de um segmento ou o preenchimento de falha óssea utilizando-se enxerto ou implante (HENRY \& WADSWORTH, 1981; BLOOMBERG et al., 1984; MORELLO et al., 2001). Biologicamente, a melhor fonte para a obtenção desse material seria, sem dúvida, o próprio animal, com a utilização do enxerto autógeno (GOLDBERG \& STEVENSON, 1987). Tal opção acaba sendo muitas vezes preterida por aumentar a morbidade, a dor, os tempos cirúrgico e anestésico e,

IDepartamento de Medicina Animal, Faculdade de Veterinária, Universidade Federal do Rio Grande do Sul (UFRGS). Av. Bento Gonçalves, 9090, Bairro Agronomia, 91540-000, Porto Alegre, RS, Brasil. E-mail: marcelo.alievi@ufrgs.br. Autor para correspondência.

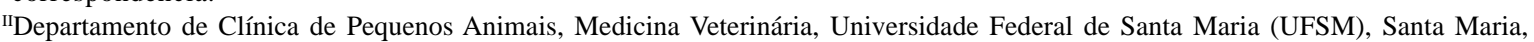
RS, Brasil.

IIIDepartamento de Clínica Médica, Universidade Federal do Mato Grosso (UFMT), Cuiabá, MT, Brasil.

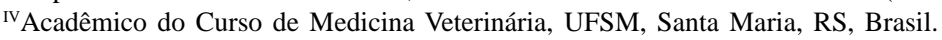


principalmente, por não fornecer volume suficiente para a reconstrução de uma grande falha óssea (MILLIS \& MARTINEZ, 2003).

Sendo assim, outras fontes de material ósseo têm sido buscadas. A principal são os ossos obtidos a partir de animais da mesma espécie, ou seja, os aloimplantes. Apesar de imunologicamente inferiores aos auto-enxertos (GOLDBERG \& STEVENSON, 1987), eles têm sido amplamente utilizados, com resultados satisfatórios (PINTO JR., 1995; MORELLO et al., 2001). Uma grande vantagem dessa alternativa é a formação de banco de ossos, o que elimina a dificuldade de se encontrar um doador disponível e apropriado para o fornecimento emergencial de aloimplantes, além de um único doador fornecer vários segmentos ósseos (KERWIN et al., 1991).

São utilizados diversos métodos e meios para conservação desses ossos: congelamento (SINIBALDI, 1989; MORELLO et al., 2001), liofilização (SCHENA et al., 1984), glicerina (COSTA, 1996), tintura de iodo a 2\% (PINTO JR., 1995), óxido de etileno (JOHNSON et al., 1985) e mel (MSCHVIDOBADSE, 1978; AMENDOLA, 2001; GAIGA, 2002). Apesar dos bons resultados na preservação e na incorporação do implante, os métodos de congelamento e a liofilização requerem equipamentos sofisticados e de alto custo. A glicerina tem baixo custo, mas não preserva as propriedades biomecânicas e a esterilidade do osso (MELO et al., 1998; DEL CARLO et al., 1999). Já o óxido de etileno, apesar de eliminar a contaminação do osso conservado, altera suas propriedades biomecânicas e o predispõe a falhas (JOHNSON \& STEIN, 1988; WAGNER et al., 1994). Uma opção seria a conservação óssea em mel, já que tem baixo custo, é de fácil obtenção, não requer material especializado (AMENDOLA, 2001) e possui propriedades antimicrobianas (EFEM et al., 1992; COOPER et al., 1999). O mel já foi utilizado na conservação de pele (GUPTA, 1977; SUBRAHMANYAM, 1993), córnea (ABRAMOV \& MARKICHEVA, 1983) e pequenos segmentos ósseos (AMENDOLA, 2001), obtendo resultados satisfatórios.

O presente experimento foi realizado com o objetivo de avaliar clínica e radiograficamente o uso de implante ósseo cortical alógeno conservado em mel no reparo de falha segmentar em fêmur de cães, verificando a taxa de incorporação e as possíveis complicações.

\section{MATERIAL E MÉTODOS}

Como doadores, foram utilizados dois cães, fêmeas, sem raça definida, com idade estimada entre um e dois anos, peso de $15 \mathrm{~kg}$ e $16 \mathrm{~kg}$, provenientes de aulas práticas do Laboratório de Cirurgia Experimental da UFSM. Ambos apresentavam-se livres de doenças infecto-contagiosas, metabólicas e neoplásicas, ou alterações músculo-esqueléticas. Além desses animais, os próprios segmentos ósseos removidos para a confecção da falha óssea cortical foram preparados e posteriormente utilizados nos outros animais.

A colheita do implante ósseo foi efetuada em sala cirúrgica sob todos os princípios de assepsia e anti-sepsia, imediatamente após a eutanásia dos animais. A região diafisária do fêmur foi exposta conforme descrição de PIERMATTEI \& JOHNSON (2004) e, com o auxílio de uma serra oscilatória, foi efetuada a remoção de um segmento ósseo tubular de $5 \mathrm{~cm}$ dessa região. Após a remoção do periósteo, dos restos musculares, do endósteo e da medula óssea, o segmento foi lavado com solução salina estéril morna e acondicionado em frasco plástico, opaco, estéril, com capacidade para $100 \mathrm{~mL}$ e preenchido com mel de abelha não-processado e produzido a partir de flores do campo. Os frascos foram identificados com a data de colheita, a idade, o peso, o sexo e a história do doador, sendo fechados e armazenados em local escuro, à temperatura ambiente, por um período que variou de 28 a 40 dias.

Como receptores, foram utilizados 14 cães, machos e fêmeas, com idade estimada entre um e dois anos, com peso variando entre $13 \mathrm{~kg}$ e $18 \mathrm{~kg}$, provenientes do Biotério Central da UFSM. Todos foram submetidos a exame clínico geral e receberam vermífugo e vacinas, sendo submetidos a período de adaptação de no mínimo 15 dias e alimentados com ração comercial e água à vontade.

No dia anterior ao procedimento cirúrgico, os cães foram submetidos à tricotomia das faces lateral e medial da coxa direita e da região sacro-ilíaca. Em seguida, receberam banho e foram mantidos em canis individuais, permanecendo em jejum sólido e líquido de 12 e 4 h, respectivamente.

Como medicação pré-anestésica, foi administrado 0,1 $\mathrm{mg} \mathrm{kg}^{-1}$ de acepromazina. Cerca de 15 minutos depois, obteve-se acesso venoso e foram administrados $30 \mathrm{mg} \mathrm{kg}^{-1}$ de cefalotina sódica. A anestesia geral foi induzida com propofol (2-4mg kg-1) e mantida com halotano vaporizado em oxigênio a $100 \%$. Foi realizado ainda bloqueio epidural com lidocaína $2 \%$ e bupivacaína $0,5 \%$.

Após 15 minutos do bloqueio epidural e com o cão em decúbito lateral esquerdo, foi realizada a antisepsia da área cirúrgica, utilizando o método álcooliodo-álcool. A abordagem cirúrgica da porção diafisária do fêmur foi realizada conforme técnica descrita por PIERMATTEI \& JOHNSON (2004). Realizada a 
exposição da diáfise femoral, o músculo adutor magno, inserido na face caudal do fêmur, foi afastado com elevador de periósteo e, a seguir, realizada a ostectomia de segmento diafisário tubular de $5 \mathrm{~cm}$ de comprimento, com a ajuda de uma serra oscilatória. Durante a secção óssea, a área foi constantemente irrigada com solução salina estéril. Após a ostectomia, efetuou-se a seleção do implante ósseo, com medidas semelhantes às do segmento removido. O selecionado foi mantido submerso em um frasco estéril contendo solução salina estéril morna por 15 minutos para reidratação e submetido a diversas lavagens com a mesma solução. Enquanto isso, o segmento removido foi preparado, conforme técnica descrita previamente, para servir de implante em outro procedimento.

Para a fixação do implante ósseo, foi utilizada uma placa de compressão dinâmica de 10 furos, com $120 \mathrm{~mm}$ de comprimento, $10 \mathrm{~mm}$ de largura e $3 \mathrm{~mm}$ de espessura, e parafusos corticais com $3,5 \mathrm{~mm}$ de diâmetro. Após a reidratação, o implante foi fixado à placa, previamente encurvada, utilizando-se dois parafusos. Em seguida, o implante foi inserido na falha óssea e a placa fixada aos segmentos proximal e distal do fêmur, utilizando-se seis parafusos, três no fragmento proximal e três no distal. Foram primeiramente inseridos, com efeito compressivo, os dois parafusos imediatamente adjacentes ao implante. Os demais parafusos foram inseridos sem efeito compressivo. Efetuada a fixação da placa, a área foi copiosamente lavada com solução salina estéril morna. Após a fáscia lata e o tecido subcutâneo serem suturados utilizando-se poliglactina 910 em padrão contínuo simples, a pele foi suturada com mononáilon em padrão isolado simples.

Após a completa recuperação anestésica, os animais receberam flunixin meglumine (1 $\left.\mathrm{mg} \mathrm{kg}^{-1}\right)$ a cada 24 horas, por três dias. Além disso, receberam tramadol $\left(2 \mathrm{mg} \mathrm{kg}^{-1}\right)$ a cada oito horas, nas primeiras 24 horas. Como profilaxia antimicrobiana, foi administrada cefalexina (30 $\mathrm{mg} \mathrm{kg}^{-1}$ ) a cada 12 horas, por sete dias.

Todos os animais foram examinados diariamente, avaliando-se o estado geral e o aspecto da ferida cirúrgica, que foi limpa com solução salina até a remoção dos pontos de pele, aos sete dias de pósoperatório. Durante esse período, os animais permaneceram em canis individuais, realizando caminhadas assistidas três vezes ao dia. Após a remoção dos pontos, os animais foram transferidos para canis coletivos. O grau de deambulação foi estimado clinicamente, a cada dois dias, tendo como referência a escala desenvolvida por BRADEN \& BRINKER (1973): grau I - não usa nem apóia o membro; grau II - uso e apoio infreqüente do membro durante a estação e ao caminhar. Não sustenta o peso, elevando-o ao correr; grau III - uso funcional do membro. Sustentação parcial do peso; grau IV - uso funcional do membro em estação, ao caminhar e ao correr. Sustentação completa do peso.

Radiografias simples, em incidências médiolateral e crânio-caudal, foram realizadas no pósoperatório imediato e depois quinzenalmente, até os 90 dias. A partir desse período, as avaliações foram mensais, até os 360 dias. Foi avaliado o alinhamento, a estabilidade e o aspecto do implante ósseo, a migração da placa e dos parafusos e a incorporação das interfaces osso/implante. Cada interface foi considerada incorporada quando havia continuidade cortical completa e remodelamento ativo do calo ósseo.

Dois animais foram submetidos à eutanásia aos 30, 60, 90, 120, 180, 270 e 360 dias, com o objetivo de avaliar macro e microscopicamente o uso do implante ósseo conservado em mel (dados não utilizados neste artigo). Para fins estatísticos, os dois animais avaliados por apenas 30 dias não foram incluídos no cálculo da porcentagem de incorporação e de complicações.

Para a análise estatística, foi utilizado o programa estatístico SPSS, versão 8.0. Foi realizada análise comparativa do tempo de consolidação das interfaces proximal e distal. Para isso, foi utilizado o teste " $t$ " para amostras pareadas, sendo considerado significativo um $\mathrm{P}<0,05$.

\section{RESULTADOS}

Verificou-se, independentemente do tempo de conservação, aspecto macroscópico adequado dos implantes, sem fissuras ou sinais de deterioração. Observou-se, porém, que possuíam coloração amarelada, com impregnação do meio conservante em seus pequenos orifícios. A cor se perdeu em grande parte após a hidratação e as diversas lavagens com a solução salina. Quando da perfuração dos implantes para a inserção dos parafusos, observou-se maior resistência em comparação aos segmentos ósseos do leito receptor, demandando mais tempo e maior força para a perfuração. Apesar disso, não foram verificadas fissuras ou fraturas no implante.

Não foi observado nenhum caso de infecção ou deiscência da ferida cirúrgica. A utilização do membro nos diferentes tempos de avaliação está registrada na figura 1a. O grau de reabsorção do implante ósseo, nos diferentes períodos de avaliação radiográfica, está contido na figura $1 \mathrm{~b}$. O comprimento médio do implante foi de $5,03 \pm 0,15 \mathrm{~cm}$ e do fêmur de $17,16 \pm 0,99 \mathrm{~cm}$, com uma proporção implante/fêmur de $29,39 \pm 1,36 \%$. A porcentagem de incorporação das interfaces foi de $79,2 \%$ e de fratura do implante foi de 


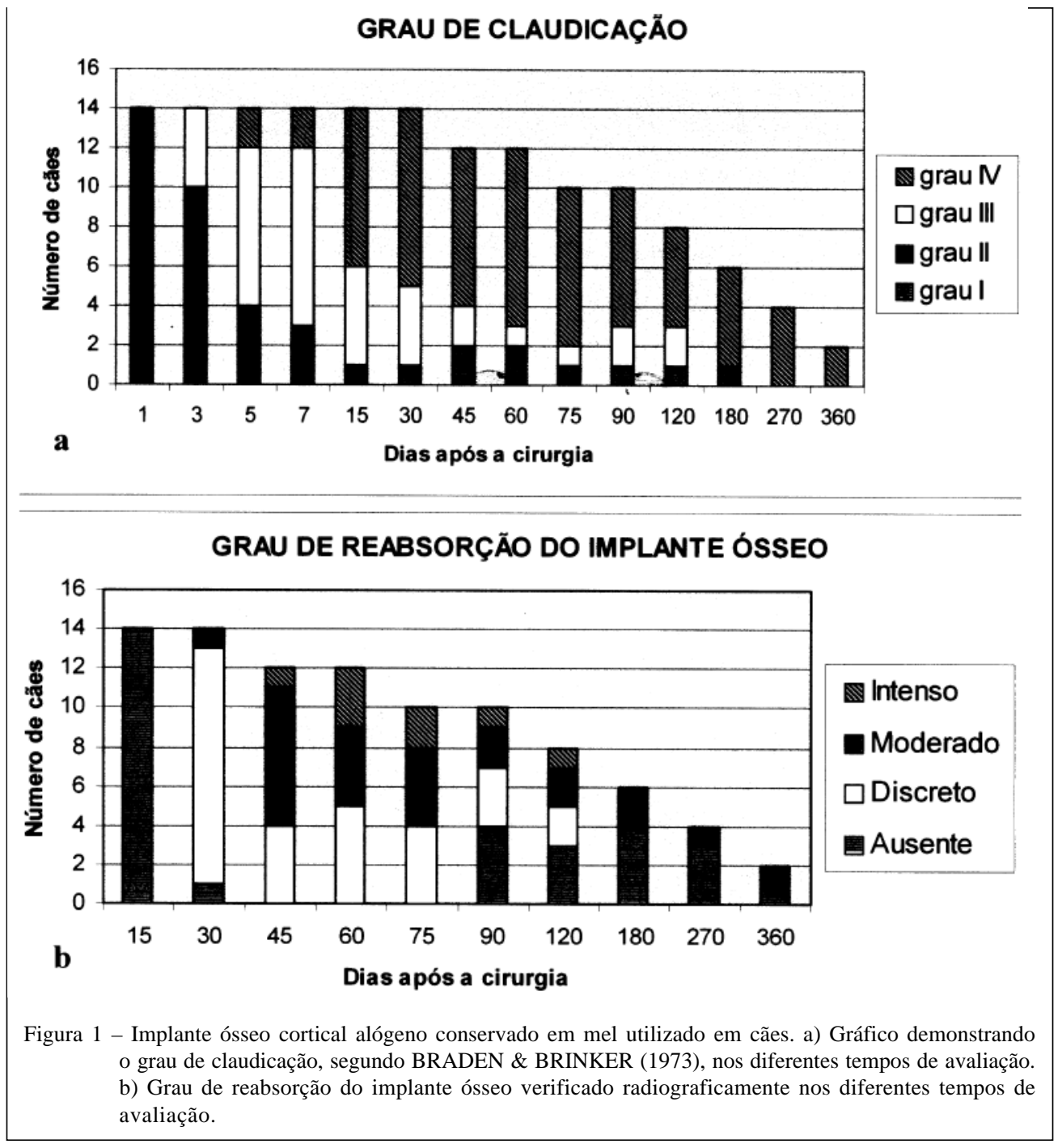

16,7\%. O tempo médio para a incorporação do implante foi de 66 dias na interface proximal e de 68,33 dias na interface distal, variando de 45 a 90 dias em ambas. Não houve diferença significativa no tempo médio para a incorporação entre as interfaces proximal e distal. As figuras 2a, 2b, 2c, 2d e 2e demonstram a evolução da incorporação do implante ósseo em um dos cães. Nos dois cães avaliados até os 30 dias, foi mantido o posicionamento da placa, dos parafusos e do implante ósseo, com leve reação periosteal nas extremidades do osso receptor, que envolvia parcialmente o implante, mas sem união dessas extremidades.

Em um dos cães, apesar da incorporação de ambas as interfaces, foi verificada intensa reabsorção, seguida de fratura na região central do implante, com posterior envergamento e quebra da placa, aos 60 e 90 dias, respectivamente (Figura 2f). Em outro animal, foi observado afrouxamento e migração do $6^{\circ}$ parafuso aos 15 dias, com leve deslocamento medial da região distal do implante, do $7^{\circ}$ e $8^{\circ}$ parafusos aos 45 dias e do $4^{\circ}$ e $5^{\circ}$ parafusos aos 60 dias. Aos 45 dias, o $8^{\circ}$ parafuso quebrou e ocorreu migração da placa. Associada a tais complicações, foi observada intensa reabsorção do implante ósseo (Figura 2g). Em um terceiro animal, registrou-se intensa reabsorção do implante, seguido de afrouxamento e migração de diversos parafusos e da placa (Figura 2h). Outro cão apresentou fissura na região central do implante após 120 dias da cirurgia, sem alteração na sua posição e no seu aspecto (Figura 2i).

\section{DISCUSSÃO}

Embora o mel seja utilizado no tratamento de enfermidades em seres vivos desde 2000 a.C., como relatam evidências encontradas no Egito

Ciência Rural, v.37, n.2, mar-abr, 2007. 


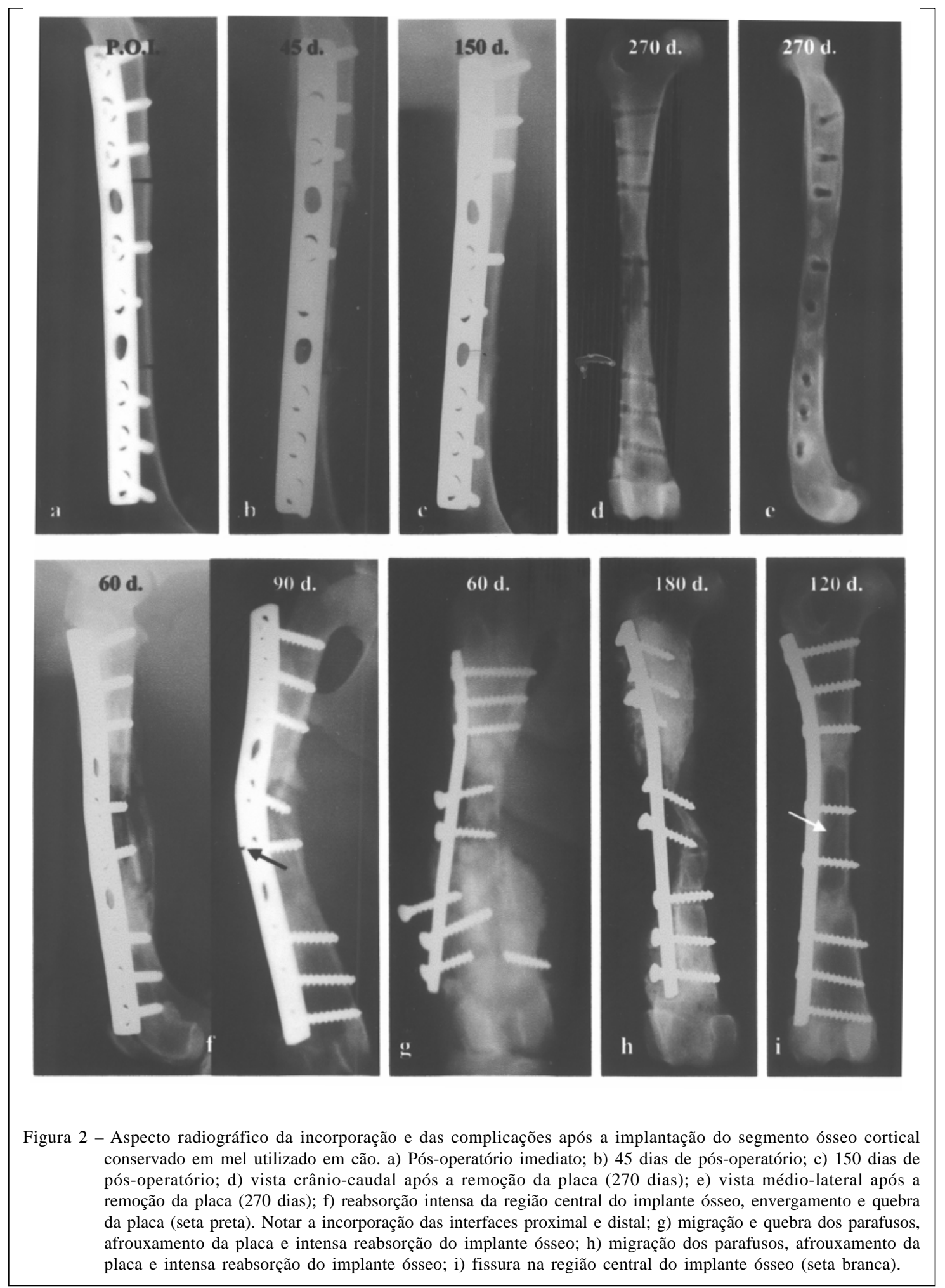

(GREENWOOD, 1993), e ter como principal indicação medicinal o tratamento de feridas (POSTMES et al., 1993), a sua escolha como meio para a preservação de implantes ósseos foi baseada principalmente nos resultados satisfatórios obtidos em pesquisas nas quais foi utilizado para a conservação de tecidos como pele (GUPTA, 1977; SUBRAHMANYAM, 1993), córnea (ABRAMOV \& MARKICHEVA, 1983) e ossos

Ciência Rural, v.37, n.2, mar-abr, 2007. 
(MSCHVIDOBADSE, 1978; AMENDOLA, 2001; GAIGA, 2002).

Apesar de alguns protocolos indicarem tempo mínimo e máximo para a manutenção do implante ósseo no meio de conservação, as únicas citações na literatura em relação ao mel provêm de dois estudos que utilizaram implantes ósseos preservados entre um e oito meses (AMENDOLA, 2001), e entre um e seis meses (GAIGA, 2002). Neste experimento, optou-se pela utilização após, no mínimo, 28 dias, não sendo observada relação entre as complicações ocorridas e o período de preservação. Recomenda-se, no entanto, estudos para definir qual o tempo mínimo e o máximo para a manutenção de implantes ósseos no mel.

Assim como citado por COSTA (1996), para glicerina 98\%, e por PINTO JR. (1995), para tintura de iodo a $2 \%$, o mel foi eficiente meio de preservação óssea à temperatura ambiente, sendo de baixo custo, fácil obtenção e dispensando equipamentos especiais para colheita e estocagem. Recomenda-se, porém, que os frascos contendo os implantes ósseos sejam mantidos em local escuro e com temperatura amena, pois tanto as altas temperaturas como a luz podem afetar as propriedades conservantes do mel (MATHEWS \& BINNINGTON, 2002).

As dimensões do defeito utilizado no experimento foram estabelecidas para reproduzir uma situação real, em que não seria possível a reconstrução completa com a aplicação de enxerto autógeno, biologicamente mais adequado (GOLDBERG \& STEVENSON, 1987). O defeito de $5 \mathrm{~cm}$, que representou cerca de $30 \%$ do comprimento do fêmur, foi $1 \mathrm{~cm}$ maior do que o estabelecido por COSTA (1996), e igual ao desenvolvido por SCHENA et al. (1984), implicando requerimento biomecânico intenso ao implante. Tal modelo não invalida os experimentos que utilizaram pequenos fragmentos ósseos, mas possibilita, por outro lado, uma extrapolação direta dos resultados obtidos experimentalmente para os casos clínicos.

Dentre as várias opções para fixar o implante, como fixação esquelética externa associada a um pino intramedular (BLOOMBERG et al., 1984), haste intramedular bloqueada (MUIR \& JOHNSON, 1995) e pinos intramedulares (PINTO JR., 1995), foi escolhido o método consagrado: placa metálica compressiva e parafusos. A vantagem é exatamente a estabilidade e a compressão que este método proporciona nas interfaces implante/receptor, fatores fundamentais para incorporação (HENRY \& WADSWORTH, 1981). Tal método de imobilização permitiu ainda o uso funcional do membro operado imediatamente após a cirurgia, evitando o surgimento das complicações advindas de sua não-utilização (BRADEN \& BRINKER, 1973).
O protocolo radiográfico instituído neste experimento foi similar ao efetuado por SCHENA et al. (1984) e, apesar de COSTA (1996) sugerir que tal exame deveria ser realizado semanal ou, no máximo, quinzenalmente, o protocolo utilizado mostrou-se adequado, pois permitiu definir o tempo aproximado para a incorporação do implante, que ocorreu até o $90^{\circ}$ dia, período em que o intervalo de cada exame foi menor, e verificar as complicações em médio e longo prazo, quando este foi maior.

A diminuição da densidade radiográfica do implante iniciada aos 30 e mantida até os 75 dias, assim como encontrado por AMENDOLA (2001), pode ser explicada pelo fato de que a atividade osteoclástica precede a osteoblástica (STEVENSON \& HOROWITZ, 1992; BAUER \& MUSCHLER, 2000). O tempo médio para a incorporação do implante foi similar ao encontrado por COSTA (1996), que utilizou implantes ósseos conservados em glicerina 98\%, e por PINTO JR. (1995), que os conservou em tintura de iodo a $2 \%$. O reparo, conforme classificação de BURCHARDT (1983), foi o do tipo 1 - isto é, reparo normal, em que a união com o leito receptor se dá em até 16 semanas, o que, segundo o autor, sugere mínima ou insignificante diferença imunológica entre o doador e o receptor.

Apesar da conclusão de AMENDOLA (2001) de que o período de 60 dias de pós-operatório seria suficiente para a verificação dos fenômenos ocorridos em um implante ósseo cortical, os resultados do presente estudo indicam que há necessidade de avaliação mais prolongada, que permita identificar, além do tempo para a incorporação do implante as complicações tardias. Tal fato corrobora os achados de ORTIZ-CRUZ et al. (1997), MANKIN et al. (1983) e THOMPSON JR. et al. (2000), que demonstraram alta taxa de complicações tardias em pacientes humanos submetidos a reconstruções de falhas ósseas com aloenxertos.

Nos dois cães em que foi observada inicialmente reabsorção precoce do implante com envergamento e fratura da placa ou afrouxamento dos parafusos e migração da placa, sugere-se possível processo de rejeição do implante, pois, conforme STEVENSON \& HOROWITZ (1992), infere-se rejeição quando tais eventos acontecem. Outro fato importante verificado nestes episódios é que, além da função biológica, os implantes provêm suporte estrutural para o tecido receptor (GOLDBERG \& STEVENSON, 1987). No animal que inicialmente apresentou migração de um parafuso e conseqüente deslocamento medial do implante ósseo, seguido de afrouxamento de outros dois parafusos e da quebra de um deles, observou-se ambiente mecânico inadequado e reabsorção intensa 
do implante ósseo, o que ratifica as afirmações de SINIBALDI (1989), STEVENSON \& HOROWITZ (1992) e de BAUER \& MUSCHLER (2000), de que a incorporação é um processo complexo dependente não apenas das propriedades biológicas do implante e da resposta do leito receptor, mas também da estabilidade da fixação e da resistência mecânica do próprio implante.

A fissura verificada em um implante ósseo após 120 dias da cirurgia pode ter sido originada pela fragilização decorrente das perfurações para a fixação dos parafusos, conforme citado por THOMPSON JR. et al. (2000). Os mesmos autores comentaram que o problema pode ser reduzido quando se utiliza haste intramedular bloqueada, caso em que o implante não é perfurado.

A taxa de 20,83\% de não-união encontrada no experimento pode ser considerada aceitável, já que, conforme MANKIN et al. (1983), espera-se um valor próximo aos 11\% e, segundo ORTIZ-CRUZ (1997), o valor pode chegar a $30 \%$. Uma opção para reduzir essa taxa seria a aplicação de auto-enxerto esponjoso nas interfaces implante/osso receptor (SINIBALDI, 1989; MORELLO et al., 2001), pois, segundo STEVENSON (1998), o osso esponjoso, com sua superfície de contato composta por células primordiais ou osteoblastos ativos, tem obviamente um potencial muito maior de formação de osso novo do que o osso cortical.

\section{CONCLUSÕES}

Os resultados obtidos permitem concluir que o implante ósseo cortical alógeno conservado em mel utilizado no reparo de falha óssea de 30\% do comprimento do fêmur em cães apresenta taxa de incorporação de 79,2\%, estando sujeito a complicações como não-união, reabsorção e fratura.

\section{CONDUTA ÉTICA}

Todos os procedimentos observaram os princípios éticos na experimentação animal, conforme recomendação do Colégio Brasileiro de Experimentação Animal (COBEA). O projeto foi aprovado pelo Comitê de Ética da Faculdade de Veterinária da UFRGS, sendo registrado sob número 05-2006.

\section{REFERÊNCIAS}

ABRAMOV, V.G.; MARKICHEVA, N.A. Therapeutic lamelar keratoplasty with honey preserved material. Oftalmol Zh, v.38, n.2, p.81-83, 1983.

AMENDOLA, G.F. Correção de defeito ósseo femural em cães utilizando implante ósseo cortical homólogo conservado em mel. 2001. 46f. Dissertação (Mestrado em Medicina Veterinária) - Universidade Federal de Santa Maria.
BAUER, T.W.; MUSCHLER, G.F. Bone grafts materials: an overview of the basic science. Clin Orthop Relat Res, n.371, p.10-27, 2000.

BLOOMBERG, M.S. et al. Frozen diaphyseal bone allografts combined with external and internal pin splintage in small animal orthopedic surgery. J Am Anim Hosp Assoc, v.20, n.3, p.393402, 1984.

BRADEN, T.D.; BRINKER, W.O. Effect of certain internal fixation devices on functional limb usage in dogs. J Am Vet Med Assoc, v.162, n.8, p.642-646, 1973.

BURCHARDT, H. The biology of bone graft repair. Clin Orthop Relat Res, n.174, p.28-42, 1983.

COOPER, R.A. et al. Antibacterial activity of honey against strains of Staphylococcus aureus from infected wounds. J R Soc Med, v.92, n.6, p.283-285, 1999.

COSTA, J.L.O. Reconstrução de grande falha óssea com enxerto cortical alógeno conservado em glicerina, fixado com placa e parafusos de aço inoxidável da série 304 . Estudo experimental em cães (Canis familiaris). 1996. 100f. Dissertação (Mestrado em Medicina Veterinária) Universidade Estadual Paulista.

DEL CARLO, R.J. et al. Aloenxertos ósseos caninos diferentemente preservados. Rev Bras Cienc Vet, v.6, n.3, p.121-126, 1999.

EFEM, S.E.E. et al. The antimicrobial spectrum of honey and its clinical significance. Infection, v.20, n.4, p.227-229, 1992.

GAIGA, L.H. Osteossíntese de úmero por xenoenxerto ósseo preservado em glicerina a $98 \%$ ou mel em pombos domésticos (Columba livia). 2002. 45f. Dissertação (Mestrado em Medicina Veterinária) - Universidade Federal de Santa Maria.

GOLDBERG, V.; STEVENSON, S. Natural history of autografts and allografts. Clin Orthop Relat Res, n.225, p.7-16, 1987.

GREENWOOD, D. Honey for superficial wounds and ulcers. Lancet, v.341, n.8837, p.90-91, 1993.

GUPTA, M. Preservation of split skin grafts in honey: a preliminary study. Indian J Surg, v.11, p.591-598, 1977.

HENRY, W.B.; WADSWORTH, P.L. Diaphyseal allografts in the repair of long bones fractures. J Am Anim Hosp Assoc, v.17, n.4, p.525-534, 1981.

JOHNSON, A.L. et al. Preliminary study of ethylene oxide sterilization of full-thickess cortical allografts used in segmental femoral fracture repair. Am J Vet Res, v.46, n.5, p.10501056, 1985.

JOHNSON, A.L.; STEIN, L.E. Morphologic comparison of healing patterns in ethylene oxide-sterilized cortical allografts and untreated cortical autografts in the dog. Am J Vet Res, v.49, n.1, p.101-105, 1988.

KERWIN, S.C. et al. Bone grafting and banking. Comp Cont Educ Pract Vet, v.13, n.10, p.1558-1563, 1991.

MANKIN, H.J. et al. Clinical experience with allograft implantation. Clin Orthop Relat Res, n.174, p.69-86, 1983. 
MATHEWS, K.A.; BINNINGTON, A.G. Wound management using honey. Comp Cont Educ Pract Vet, v.24, n.1, p.53-60, 2002 .

MELO, E.G. et al. Aloenxerto ósseo cortical: avaliação do seu emprego em tíbia de cão. Arq Bras Med Vet Zootec, v.50, n.4, p.385-394, 1998.

MILLIS, D.L.; MARTINEZ, S.A. Bone grafts. In: SLATTER, D. Textbook of small animal surgery. 3.ed. Philadelphia: Saunders, 2003. V.2, cap.133, p.1875-1891.

MORELLO, E. et al. Bone allografts and adjuvant cisplatin for the treatment of canine appendicular osteosarcoma in 18 dogs. J Small Anim Pract, v.42, n.2, p.61-66, 2001.

MSCHVIDOBADSE, V.M. Allotransplantation sterilisierter Knochen und Halbgelenke bei Knochendefekten. Zentralbl Chir, v.103, n.17, p.1138-1148, 1978.

MUIR, P.; JOHNSON, K.A. Tibial intercalary allograft incorporation: comparison of fixation with locked intramedullary nail and dynamic compression plate. J Orthop Res, v.13, n.1, p.132-137, 1995

ORTIZ-CRUZ, E. et al. The results of transplantation of intercalary allografts after resection of tumors. J Bone Joint Surg Am, v.79A, n.1, p.97-106, 1997.

PIERMATTEI, D.L.; JOHNSON, K.A. The hindlimb. In:____ An atlas of surgical approaches to the bones and joints of the dog and cat. 4.ed. Philadelphia: Saunders, 2004. Section VII, p.329-391.
PINTO JR., H.S. Utilização de enxerto ósseo cortical homólogo preservado em tintura de iodo a $2 \%$ na reparação de fraturas cominutivas de ossos longos de cães. 1995. 75f. Tese (Doutorado em Medicina Veterinária) - Universidade de São Paulo.

POSTMES, T. et al. Honey for wounds, ulcers and skin graft preservation. Lancet, v.341, n.8847, p.756-757, 1993.

SCHENA, C.J. et al. Segmental freeze-dried and fresh cortical allografts in the canine femur. I- a sequential radiographic comparison over a one-year time interval. J Am Anim Hosp Assoc, v.20, n.6, p.911-922, 1984.

SINIBALDI, K. Evaluation of full cortical allografts in 25 dogs. J Am Vet Med Assoc, v.194, n.11, p.1570-1577, 1989.

STEVENSON, S. Enhancement of fracture healing with autogenous and allogeneic bone grafts. Clin Orthop Relat Res, n.355S, p.S239-S246, 1998.

STEVENSON, S.; HOROWITZ, M. Current concepts review the response to bone allografts. J Bone Joint Surg Am, v.74A, n.6, p.939-950, 1992

SUBRAHMANYAM, M. Storage of skin grafts in honey. Lancet, v.341, n.8836, p.63-64, 1993.

THOMPSON JR., R.C. et al. Fractures in large segment allografts. Clin Orthop Relat Res, n.370, p.227-235, 2000.

WAGNER, S.D. et al. Failure of ethylene oxide-sterilized cortical allografts in two dogs. J Am Anim Hosp Assoc, v.30, n.2, p.181-189, 1994. 